\title{
Laser metal deposition of copper on diverse metals using green laser sources
}

\author{
Himani Siva Prasad ${ }^{1}$ (D) Frank Brueckner ${ }^{1,2} \cdot$ Joerg Volpp ${ }^{1} \cdot$ Alexander F. H. Kaplan ${ }^{1}$
}

Received: 19 June 2019 / Accepted: 18 February 2020 /Published online: 3 March 2020

(C) The Author(s) 2020

\begin{abstract}
Green laser sources are advantageous in the processing of copper due to the increase of absorptivity compared with more commonly available infrared lasers. Laser metal deposition of copper with a green laser onto various substrate metals namely copper, aluminium, steel and titanium alloy was carried out and observed through high-speed imaging. The effects of process parameters such as laser power, cladding speed and powder feed rate, and material attributes such as absorptivity, surface conditions and thermal conductivity are tied together to explain the size and geometry of the melt pool as well as the fraction of the power used for melting material. The copper substrate has the smallest melt pool with a high angle, followed by aluminium, steel and titanium alloy. The incorporation times for powder grains in the melt pools vary based on the substrate materials. Its dependency on material properties, including surface tension forces, melting temperatures and material density, is discussed. Oxide skins present on melt pools can affect powder incorporation, most significantly on the aluminium substrate. The lower limits of the fraction of power irradiated on the surface used purely for melting were calculated to be $0.73 \%, 2.94 \%, 5.95 \%$ and $9.78 \%$ for the copper, aluminium, steel and titanium alloy substrates, respectively, showing a strong dependence on thermal conductivity of the substrate material. For a copper wall built, the fraction was $2.66 \%$, much higher than a single clad on a copper substrate, due to reduced workpiece heating. The results of this paper can be transferred to other metals with low absorptivity such as gold.
\end{abstract}

Keywords Copper · Laser metal deposition · Additive manufacturing · High-speed imaging · Multi-material · Green 515-nm laser $\cdot$ Directed energy deposition $\cdot$ Absorptivity $\cdot$ Powder grain incorporation $\cdot$ LMD $\cdot$ DED

\section{Introduction}

Additive manufacturing is a technology through which components are manufactured by adding material in layers. There are two main types of powder-based additive manufacturing

Himani Siva Prasad

Himani.Siva.Prasad@1tu.se

Frank Brueckner

Frank.Brueckner@iws.fraunhofer.de

Joerg Volpp

Jorg.Volpp@1tu.se

Alexander F. H. Kaplan

Alexander.Kaplan@ltu.se

1 Department of Engineering Sciences and Mathematics, Luleå University of Technology, 97187 Luleå, Sweden

2 Fraunhofer IWS, Winterbergstrasse 28, 01277 Dresden, Germany using laser as the main heat source: blown powder and preplaced powder. Blown powder laser additive manufacturing, also called laser metal deposition (LMD), is a process where metal powder is fed into a melt pool created by the laser beam to produce a fully dense near net-shaped component, as described by e.g. Gibson et al. [9]. These additive manufacturing methods can be used to produce structures that cannot be manufactured through conventional processes, e.g. Brueckner et al. [8] wrote about locally tailored material properties and in situ alloying among others. It was shown that linearly graded transitions between miscible material combinations could be achieved through LMD. LMD can also be applied to material combinations that have required and beneficial, limited or no miscibility.

Pogson et al. [17] mention that copper structures of increasing importance such as micro-heat exchangers are difficult to manufacture through conventional methods. Popovich et al. [18] summarised that the high electrical and thermal conductivity of copper along with good corrosion resistance makes 
copper an interesting material for tooling inserts and cooling components as well as in electrical components when it is precipitation strengthened or alloyed. Selective laser melting of dense copper structures was reported by Lykov et al. [13], and thin-walled honeycomb structures by Pogson et al. [17]. Deposition of a functionally gradient material with varying fractions of copper and nickel through LMD has been carried out with a $\mathrm{CO}_{2}$ laser by Mazumder and Stiles [16]. Imran et al. [12] succeeded at depositing tool steel powder onto a copper substrate through LMD, with and without a buffer layer, intended to make bimetallic tooling using a $\mathrm{CO}_{2}$ laser.

There is a material-based variation in electromagnetic absorption, e.g. Brueckner et al. [8]. The wavelengthdependent absorption of electromagnetic radiation in twelve different materials, plotted based on spectral reflectance data from the work of Spisz et al. [21], can be found in Fig. 1. The surface condition is described as 'as received' and cleaned, which can be assumed to be smooth but not ideal. The transmission of radiation through a material depends on material type, thickness and the wavelength of radiation used. Metals, that are not thin films, are opaque to visible and infrared (IR) wavelengths [5].

Bourell et al. [6] explain that it is difficult to create a melt pool for highly reflective (resulting in low absorption) alloys such as copper and aluminium. Asano et al. [2] used a blue direct diode laser to deposit a copper film through a blown powder process on type 304 stainless steel. Due to the high absorptivity of the blue light in copper, clads could be deposited with laser power as low as $56 \mathrm{~W}$. Table 1 lists spectral absorptance for various metals for $457 \mathrm{~nm}, 525 \mathrm{~nm}$ and $1085 \mathrm{~nm}$ which are close to the wavelengths of blue, red and IR lasers respectively. It is clear that the increase in absorptance between IR and green lasers is much higher than that
Table 1 Values for spectral absorptance for copper, aluminium, stainless steel and aluminium for wavelengths close to blue, green and IR laser wavelengths, from Spisz et al. [21]

\begin{tabular}{lllll}
\hline Wavelength $(\mathrm{nm})$ & \multicolumn{4}{l}{ Spectral absorptance for material $(\%)$} \\
\cline { 2 - 5 } & Copper & Aluminium & Stainless steel & Titanium \\
\hline 457 (blue laser) & 65.2 & 13.6 & 43.2 & 80.8 \\
525 (green laser) & 54.5 & 13.5 & 40.2 & 78.6 \\
1085 (IR laser) & 4.0 & 5.2 & 30.1 & 65.2 \\
\hline
\end{tabular}

between green and blue laser systems. High-power green laser systems are now commercially available, and are more accessible than blue laser systems. Use of green lasers with wavelength close to $500 \mathrm{~nm}$ would increase the absorption of laser radiation in copper by more than ten times compared with 1070-nm lasers.

Hess et al. [10] demonstrated welding of copper using 515$\mathrm{nm}$ and 1030-nm lasers combined. Using only an IR laser with the same line energy, only heat conduction welding could be carried out on copper.

\subsection{Material property impact on laser-generated melt pool dimensions}

A number of physical factors related to the substrate and powder materials as well as their surface condition play a role in determining the melt pool size and geometry. Absorptivity of the wavelength of the laser radiation is of high importance, determining how much energy radiated onto the surface is absorbed and used in the process. From Fig. 1, it can be seen that the spectral absorptance for various metals decreases with increasing wavelength. Absorptivity is temperature

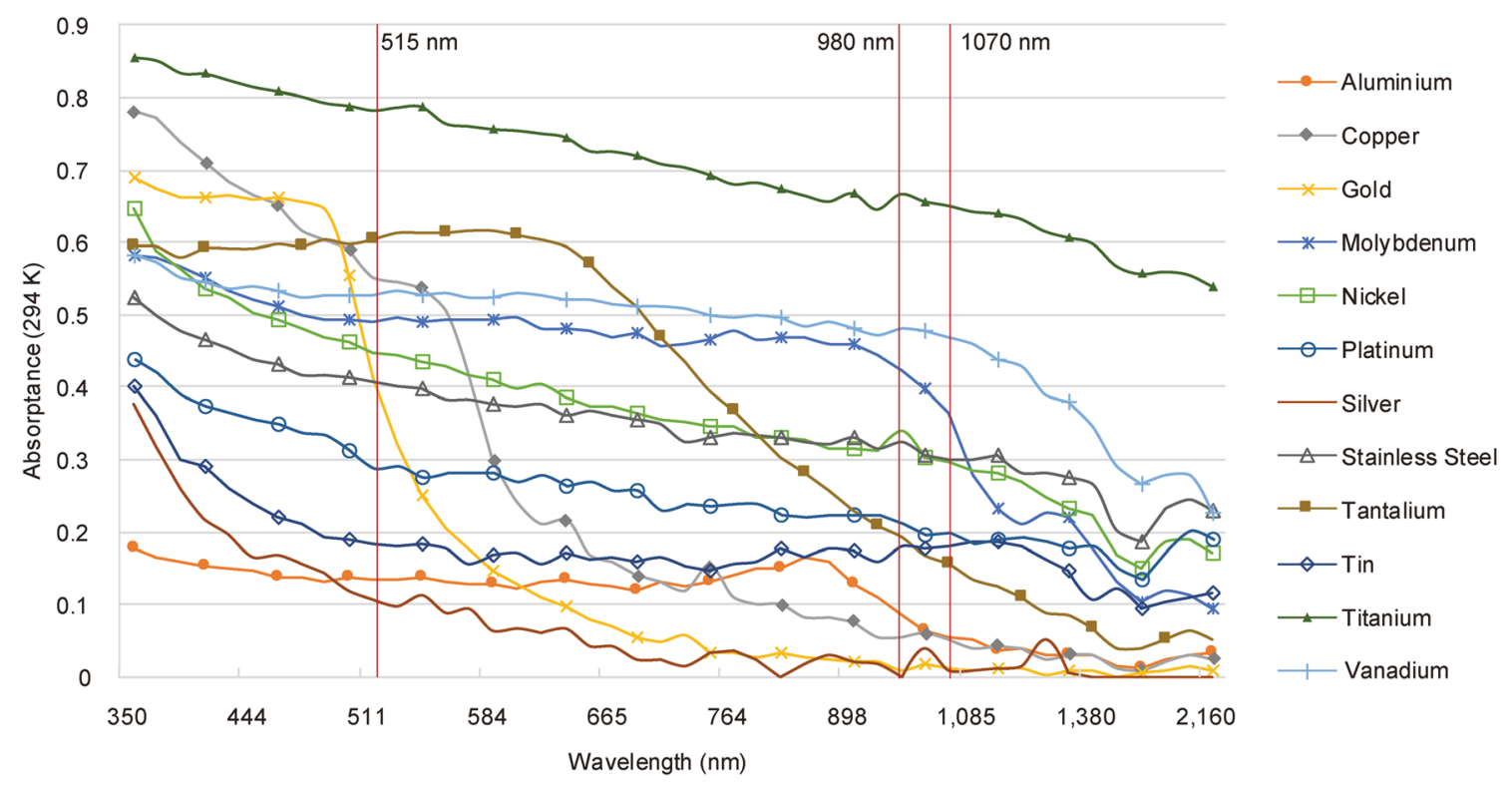

Fig. 1 Spectral absorptance for various high-purity metals with a cleaned but not ideal surface finish plotted using data from Spisz et al. [21] 
dependent. Bergström [5] summarised that it can generally be described to increase linearly with temperature in their solid phase. On undergoing the solid-liquid transition, the increase in absorptivity is in the order of $150-200 \%$ after which it continues to increase linearly.

Surface roughness present on surfaces favours the absorption of laser radiation as explained by Bergström [5], i.e. sandblasted surfaces absorb more radiation than polished surfaces. Oxide layers found on most metal surfaces can also help in increasing absorption. Tolochko et al. [22] write that powder materials absorb more radiation than dense materials in general mainly due to multiple reflections. The temperature of powder grains also rises faster due to their small volume. This is significant in the case of LMD, where the powder grains can be heated by the laser beam before they reach the melt pool.

An important factor that plays a role in the formation of the laser-generated melt pool and its properties is thermal conductivity, which describes the rate of heat transfer from the hot to the cold end of the material. Copper at room temperature has high thermal conductivity ( $385 \mathrm{~W} / \mathrm{mK})$, implying that heat is quickly lost to the colder parts of the substrate. Mazumder [15] mentions that convection is the most important factor influencing the melt pool geometry, including aspect ratio and shape. It is also said to dominate alloying (or dilution) in laser cladding-like processes. An influence on convection is the viscosity of the molten material, whose value is also a temperature-based gradient. Melting and vaporisation temperatures of the material are also significant in determining melt pool properties.

\subsection{High-speed imaging}

High-speed imaging is an effective tool for studying process behaviour. A video of the process is captured at a high frame rate ranging from few hundred frames per second to multiple hundred thousand frames per second, and later played back at lower speeds. Phenomena that are generally difficult to observe then become visible. The concept of using high-speed imaging to observe laser processes dates back to 1985, when Arata et al. [1] studied high-power $\mathrm{CO}_{2}$ laser welding. LMD has been studied through high-speed imaging by Siva Prasad et al. [20], who described the powder catchment behaviour of Inconel 718 deposited on stainless steel.

Although it is known that various material properties have an effect on the melt pool properties, these results are not available in a visual and comprehensive way elsewhere. This paper discusses and compares the effects in various metals influencing the laser-generated melt pool in various substrate metals with observations from high-speed imaging. Incorporation behaviour of powder grains in the melt pool is also compared among the substrate materials.

\section{Methodology}

Single tracks of $99.9 \%$ pure copper were cladded onto various substrates, listed in Table 2. The feedstock of copper powder was of size 50 to $90 \mu \mathrm{m}$. A coaxial ring-slit nozzle was used for the deposition where the laser beam and shielding gas travel through a central hole and the powder along with the carrier gas is fed through the surrounding slit. Argon was used as both the carrier and shielding gases. Both the powder and laser beam interact before reaching the melt pool surface.

A frequency-doubled disk laser source with effective wavelength $515 \mathrm{~nm}$ and maximum power $1 \mathrm{~kW}$ was used with spot size at focus of $1.7 \mathrm{~mm}$ and Gaussian distribution. A number of parameters with power ranging from $200 \mathrm{~W}$ to $1 \mathrm{~kW}$, travel speed from 0.1 to $0.5 \mathrm{~m} / \mathrm{min}$ and powder feed rate from 0.65 to $3.9 \mathrm{~g} / \mathrm{min}$ were used to create the tracks on the listed substrates.

High-speed imaging was used to study the process behaviour from the side. The processes were filmed using a highspeed camera at a recording frequency of 10,000 frames per second (fps), making the shortest observable time step $0.1 \mathrm{~ms}$. Continuous wave laser illumination with wavelength $808 \mathrm{~nm}$ and maximum power of $100 \mathrm{~W}$ was used to illuminate the process. A narrow band-pass filter matching the wavelength of the illumination laser was used to block out the processing laser light. The camera was angled at $30^{\circ}$ horizontally to capture the process. The process setup can be found in Fig. 2(a) and a cross-section image of the process is in Fig. 2(b).

The videos were played back at low speeds to observe the melt pool dynamics, powder catchment behaviour and solidification properties. Cross sections of the tracks were made to observe dilution and track shapes. Surface images were also taken. Image processing software was used to measure melt pool length, track width, track height from the surface of the substrate, melting depth and area of the melted regions in the cross section.

\section{Results and discussion}

Copper tracks were successfully cladded onto the four substrate materials: copper, aluminium, steel and titanium alloy. A wall of copper was built on the steel substrate showing the possibilities of multilayer processing with copper powder

Table 2 List and specifications of the substrate materials

\begin{tabular}{ll}
\hline Substrate material & Specification \\
\hline Copper (sandblasted) & $99.9 \%$ copper \\
Aluminium (sandblasted) & $99.6 \%$ aluminium (EN-AW 1100) \\
Steel & 1.2343 (X37CrMoV5-1) \\
Titanium alloy & Ti6Al4V \\
\hline
\end{tabular}




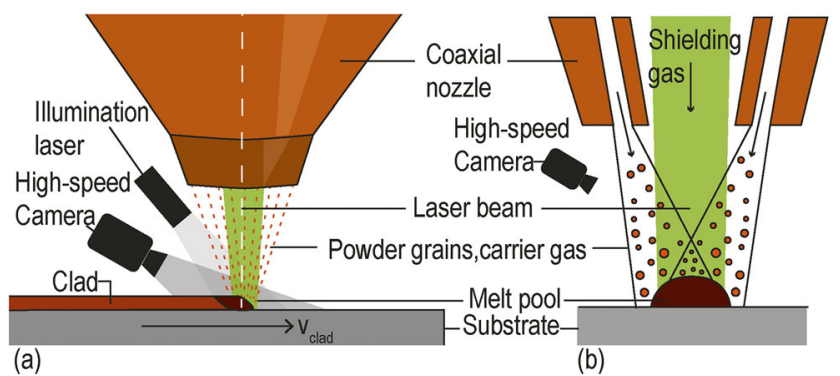

Fig. 2 Schematic illustration of the (a) side view of the experimental setup, and (b) cross section of the process overview

using the green laser; it can be seen in Fig. 3. Table 3 lists the minimum required power for the given speeds and powder feed rates for each of the substrate materials.

Measurements of the melt pool lengths from high-speed imaging of the LMD processes and cross-section images showed that:

- Melt pool length and track width generally increase with increasing power. In lieu of varying power for copper, the cladding speed was decreased in steps since the minimum power needed to create a melt pool in copper was $1 \mathrm{~kW}$. This also resulted in increasing melt pool lengths and track widths due to increased interaction time between the laser beam and the substrate.

- With increasing laser power, track height (measured from the surface of the substrate to the top of the track) is seen to increase until a certain extent, as the fraction of incorporated powder increases, and then decreases. This trend was clear in the case of the steel and titanium alloy substrates, where a wide range of power could be used $(200 \mathrm{~W}$ to $1 \mathrm{~kW})$.

- Dilution with the base material decreases with increasing powder feed rate, or/and reducing laser power. The area of cross section of the deposited track also increased with increasing powder feed rate.

Frames from high-speed imaging of copper deposition on a copper substrate can be seen in Fig. 4. The process is seen to advance intermittently, as in Fig. 4(b). As the laser beam moves forward, a molten region is seen to form on the substrate directly in front of the melt pool (in Fig. 4(b)(i)). The melt pool joins this molten region, lengthening slightly (approximately one-tenth of the melt pool length). The melt pool

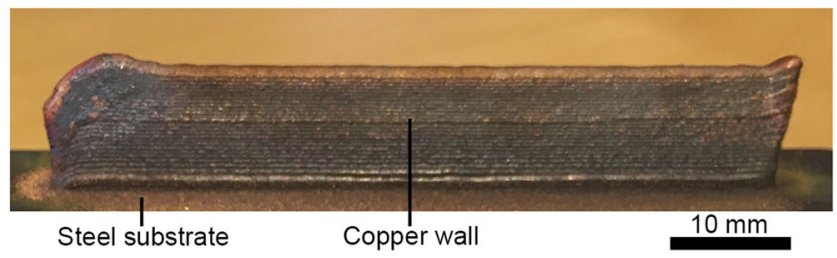

Fig. 3 Copper wall built on steel substrate
Table 3 The minimum required power for given cladding speed and powder feed rate for the four substrate materials

\begin{tabular}{lllll}
\hline Substrate material & Copper & Aluminium & Steel & Titanium alloy \\
\hline Laser beam power $(\mathrm{kW})$ & 1 & 0.6 & 0.2 & 0.2 \\
Cladding speed $(\mathrm{m} / \mathrm{min})$ & 0.1 & 0.5 & 0.5 & 0.5 \\
Powder feed rate $(\mathrm{g} / \mathrm{min})$ & 1.3 & 1.3 & 2.6 & 3.9 \\
\hline
\end{tabular}

shape and size then regularise, and a molten region starts to form in front of it again. This cycle takes about $0.12 \mathrm{~s}$.

From the high-speed imaging, as in Fig. 4, it can also be seen that there is not much melting of the base material implying low/no dilution, and the melt pool angle (the surface of the melt pool is not horizontal, it is at an angle to the horizontal) is high $\left(35^{\circ}\right.$ in this case). Since the horizontal area covered by the melt pool is low, this decreases the probability of catchment and incorporation of the fed powder grains. Waves appear on the surface of the melt pool, due to the impact of the powder grains.

The high-speed imaging sequence of the incorporation of a powder grain into the melt pool is in Fig. 4(c). In the first frame, the powder grain arrives at the surface of the melt pool. It floats on the melt pool, after which it is incorporated or sinks into the melt pool, $0.3 \mathrm{~ms}$ after first contact with the melt pool. Integration of powder grains in the melt pool can be seen to happen in as little as $0.1 \mathrm{~ms}$ from first contact. Powder grains that arrive at the edges of the melt pool may remain on the surface of the clad. They interact with the melt available and attach, or have a molten surface as a result of their interaction with the laser beam, but in either of these the powder grains are not fully melted.

Figure 5 shows frames from high-speed imaging of the process of the deposition of copper on an aluminium substrate. An oxide skin is present on the melt pool surface along the edges and moves dynamically on the surface. Some bright frothy patches are also present at the front end of the melt pool. The angle of the melt pool is also very low (almost horizontal), signifying melting and dilution of the substrate. This also increases the possibility of powder catchment in the melt pool.

Powder grains arriving at the centre of the melt pool incorporate within $0.1 \mathrm{~ms}$ of arriving at the melt pool, as in Fig. 5(b). They are not seen to be floating or moving, and likely incorporate at the position of initial impact. Some waves and movements can be spotted in the melt pool, but no small ripples are seen.

When powder grains make their initial contact with the oxide skin (marked on Fig. 5(b)(i)), there are two possible scenarios. In the first scenario, they break the oxide skin and incorporate immediately into the melt (within $0.1 \mathrm{~ms}$ ). In this case, the powder grains only require $0.1 \mathrm{~ms}$ to sink into the melt, similar to those grains that arrive at the centre of the melt 


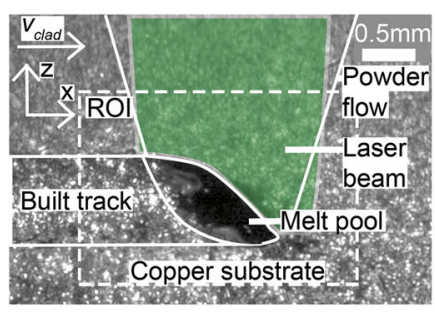

(a) Reference image

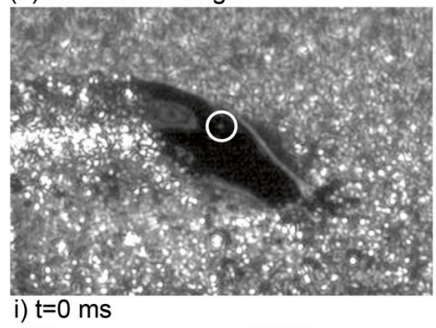

(c) Incorporation of powder grain

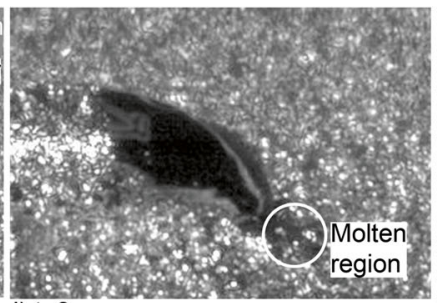

i) $\mathrm{t}=0 \mathrm{~ms}$

(b) progress of process in steps

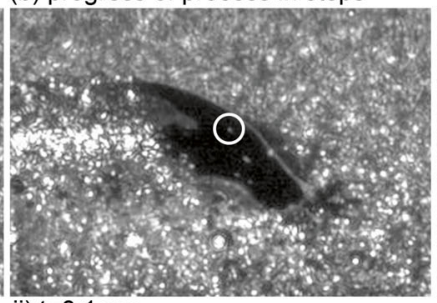

ii) $\mathrm{t}=0.1 \mathrm{~ms}$

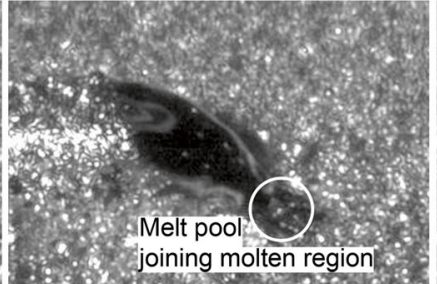

ii) $\mathrm{t}=71.4 \mathrm{~ms}$

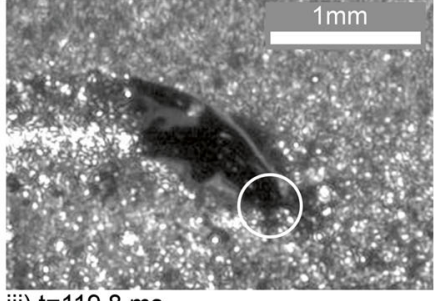

iii) $\mathrm{t}=119.8 \mathrm{~ms}$

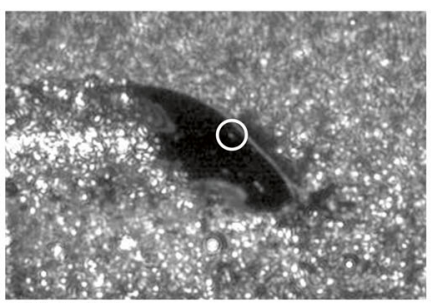

iii) $\mathrm{t}=0.2 \mathrm{~ms}$

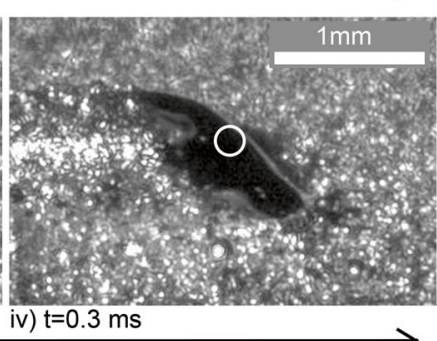

Fig. 4 Frames from high-speed imaging of copper deposition on a copper substrate using power $1 \mathrm{~kW}$, powder feed rate $1 \mathrm{~g} / \mathrm{min}$ and cladding speed $0.1 \mathrm{~m} / \mathrm{min}$. (a) Reference image indicating the region of interest. (b) Progress of the process: movement of the melt pool as the laser beam

moves forward (with white circles indicating the region of interest), and (c) incorporation of powder grains in the melt pool (the white circles mark the position of the powder grain)

pool. The second scenario is shown in Fig. 5(c). The powder grain floats on this oxide skin for an extended period of time ( $2.8 \mathrm{~ms}$ in this case) before incorporating with the melt. During this time, it might undergo melting, and might even fully melt prior to incorporation with the melt pool.

In Fig. 6, frames from the high-speed imaging of the deposition process can be seen. Along the entire edge of the melt pool, a 0.1-mm-wide oxide skin is present. Like in the case of aluminium, it floats on the melt pool and is broken up by the impact of powder grains. Figure 6(b) shows the incorporation

of arriving copper powder grains into the melt. Incorporation happens within $0.1 \mathrm{~ms}$ for most observed cases, and generally within $0.2 \mathrm{~ms}$. The melt pool appears to be flat and small ripples are formed on its surface on impact of the powder grains.

Frames from the high-speed imaging of the LMD process on a titanium alloy substrate can be found in Fig. 7. From the reference image (Fig. 7(a)), it can be seen that the melt pool is $4.82 \mathrm{~mm}$ long, and the laser beam only irradiates the first $1.7 \mathrm{~mm}$. Small patches of oxides can be seen on the melt pool
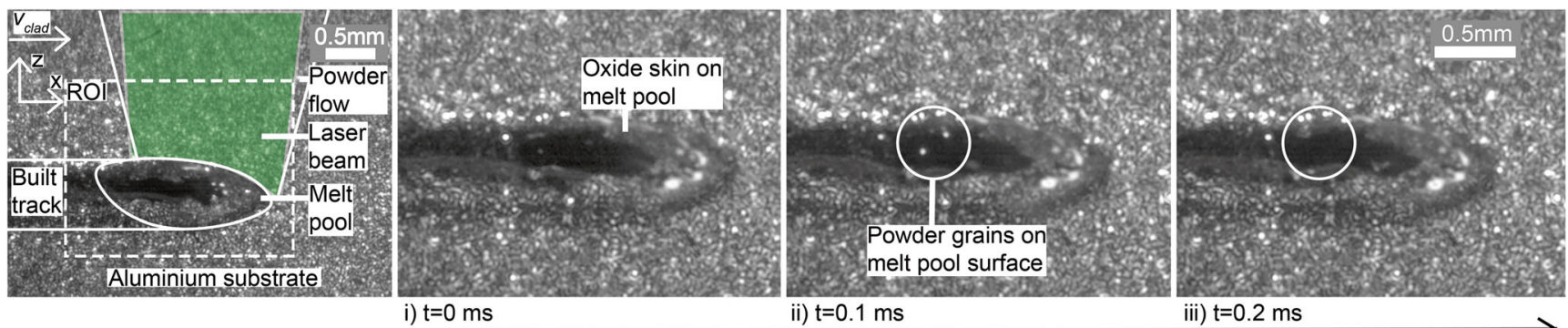

ii) $\mathrm{t}=0.1 \mathrm{~ms}$

iii) $\mathrm{t}=0.2 \mathrm{~ms}$

(a) Reference image

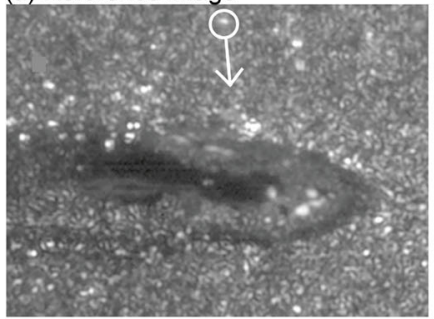

i) $\mathrm{t}=0 \mathrm{~ms}$

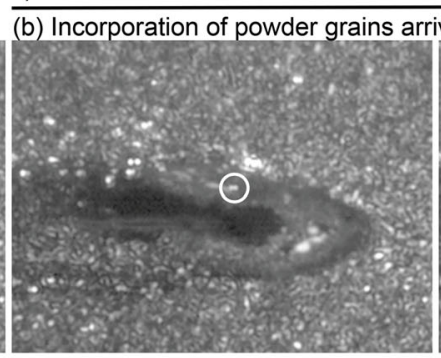

i) $\mathrm{t}=0.2 \mathrm{~ms}$

ing at the centre of the melt pool

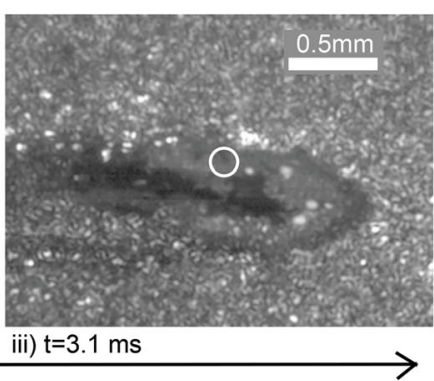

(c) Incorporation of powder grains arriving on oxide skin

Fig. 5 Frames from high-speed imaging of copper deposition on aluminium using laser power $1 \mathrm{~kW}$, cladding speed $0.5 \mathrm{~m} / \mathrm{min}$ and powder feed rate $1.3 \mathrm{~g} / \mathrm{min}$. (a) Reference image indicating region of

interest; frame sequences for (b) incorporation of powder grains into the melt pool and (c) incorporation of powder grains arriving on the oxide skin (the white circles mark the position of the powder grains) 


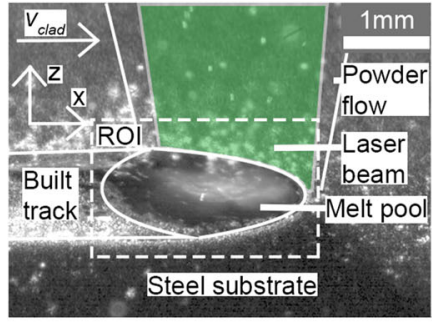

(a) Reference image

Fig. 6 Frames from high-speed imaging of copper deposited on steel using laser power $1 \mathrm{~kW}$, cladding speed $0.5 \mathrm{~m} / \mathrm{min}$ and powder feed rate $2.6 \mathrm{~g} / \mathrm{min}$ where (a) is the reference image and (b) is a frame

surface. Figure 7(b) shows the incorporation of a powder grain into the melt pool. The powder grain is incorporated within $0.1 \mathrm{~ms}$ of making first contact with the melt pool. On impact, small ripples are formed on the laser-irradiated region of the melt pool. Melt is slowly pushed towards the solidifying edge of the melt pool, which is at a higher vertical position than the front of the melt pool.

Figure 8 summarises the frames from the various highspeed videos (Fig. 8(a)), surface images (Fig. 8(b)) and cross-section images (Fig. 8(c)) of the clads on the four substrates using the same set of parameters: power $1 \mathrm{~kW}$, powder feed rate $1.3 \mathrm{~g} / \mathrm{min}$ and $0.5 \mathrm{~m} / \mathrm{min}$. Data regarding melt pool length, track width and height, depth of melting, dilution, rough values of percentage of laser power used for melting and the incorporation time observed for the same parameters are presented in Table 4 . The volume of melted material per unit time was calculated from the cross-section images, i.e. the melted area from the images multiplied by the distance travelled per unit time. It includes the volume of the clad (copper) and the volume of the substrate melted. The lower limit of the laser power used for melting is calculated as the energy needed to melt the calculated volume of material. This includes the energy to raise the temperature of the base material and copper added from room temperature to their respective melting points, as well as their respective latent heats of melting. Heat conduction from the melt pool and heating the materials above their melting temperatures are not considered. This also

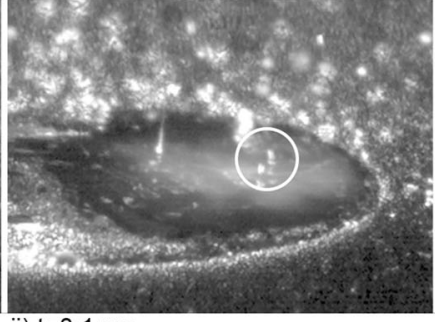

ii) $\mathrm{t}=0.1 \mathrm{~ms}$

melt pool

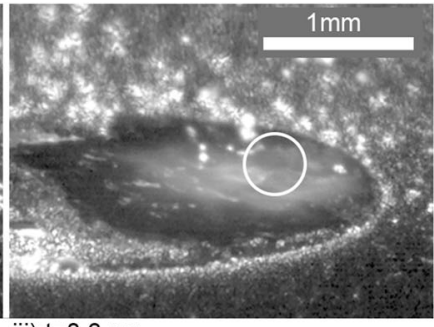

iii) $\mathrm{t}=0.3 \mathrm{~ms}$

sequence showing incorporation of powder grains into the melt pool (the white circles mark the position of the powder grains)

gives a value for the lower limit of the overall absorptivity. At the parameters selected, there is no continuous melt pool in the case of the copper substrate.

In LMD, the laser beam interacts with the melt pool, which might be composed of mainly the base material, mainly the deposited material or a mix of both the substrate and base materials depending on the extent of dilution. The absorptivity for the wavelength of the laser beam would thus depend on the mixture of materials. The size and behaviour of the melt pool depend on the properties of both the base and deposited materials, i.e. both copper and the material being observed in the paper.

From the observations made with regard to all four substrates considered, incorporation of the copper powder grains occurs most often within $0.1 \mathrm{~ms}$ after first contact with the melt pool (and maximum up to $0.2 \mathrm{~ms}$ and $0.3 \mathrm{~ms}$ in the case of steel and copper respectively). This is on average lower compared with the time taken for Inconel 718 powder grains to incorporate into the centre of a stainless steel $316 \mathrm{~L}$ melt pool as seen by Siva Prasad et al. [20]. In that case, the incorporation times ranged between 0.28 and $8.16 \mathrm{~ms}$ depending on position of initial interaction between the powder grains and the melt pool. In the observed videos, the incorporation time was so short that the particles were not seen to be accelerated on the melt pool surface by e.g. Marangoni flow.

Several factors influence the time taken for incorporation of powder grains in the melt pool. The maximum times taken

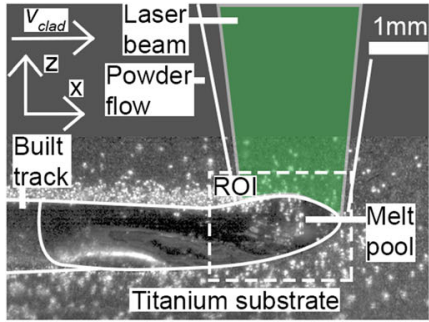

(a) Reference image

Fig. 7 Frames from high-speed imaging of copper deposited on the titanium alloy using laser power $0.6 \mathrm{~kW}$, cladding speed $0.5 \mathrm{~m} / \mathrm{min}$ and powder feed rate $3.9 \mathrm{~g} / \mathrm{min}$ where (a) is the reference image and (b) is a
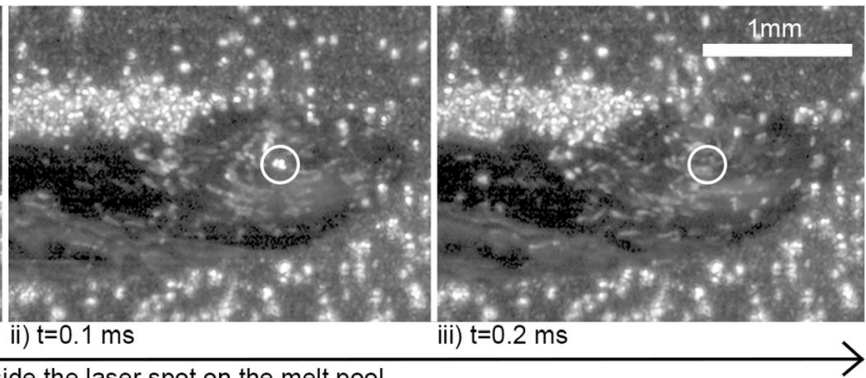

frame sequence showing incorporation of powder grains into the melt pool (the white circles mark the position of the powder grains) 

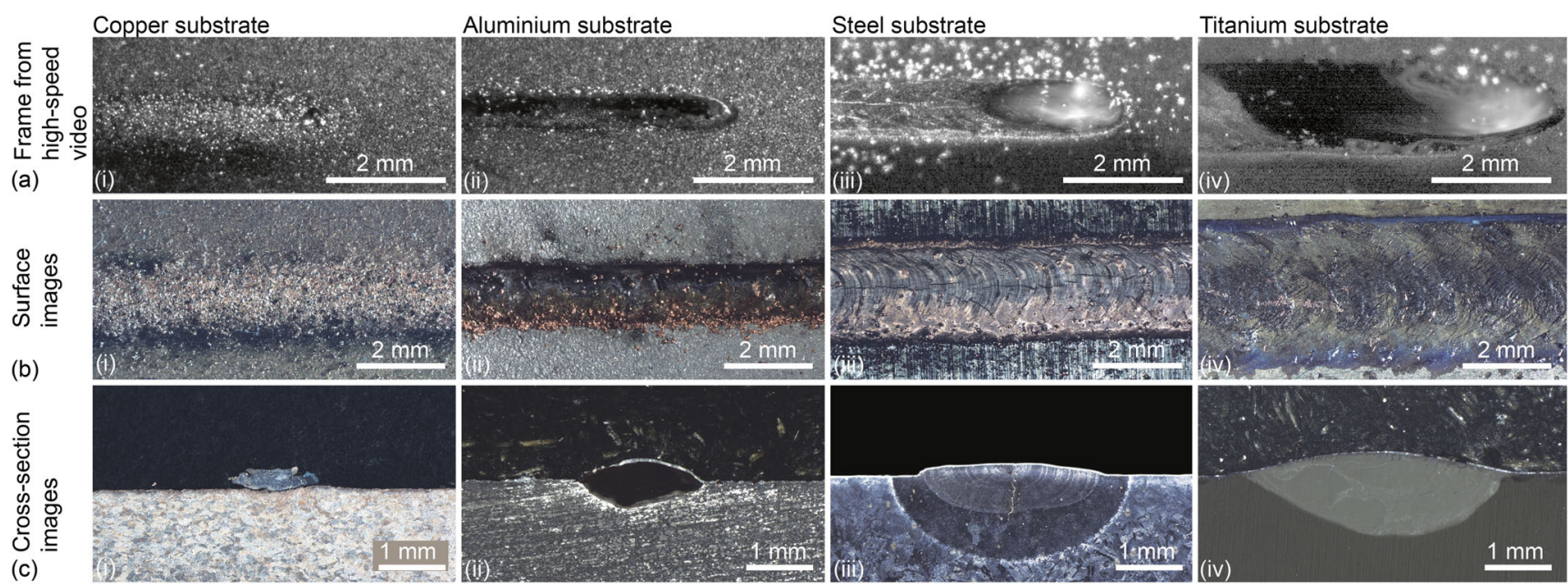

Fig. 8 (a) Frames from high-speed imaging, (b) surface images and (c) cross-section images of the clads of the LMD process of copper onto (i) copper, (ii) aluminium, (iii) steel and (iv) titanium alloy using parameters: power $1 \mathrm{~kW}$, cladding speed $0.5 \mathrm{~m} / \mathrm{min}$ and powder feed rate $1.3 \mathrm{~g} / \mathrm{min}$

for incorporation of powder grains in the melt pool were $0.1 \mathrm{~ms}$ for aluminium and titanium alloy, $0.2 \mathrm{~ms}$ for steel and $0.3 \mathrm{~ms}$ for copper for the same feed material and parameter set. The influence of kinetic energy of the powder grains and the effects due to irradiation of the laser beam on the fed powder before they reach the melt pool can be considered the same for all the substrate materials used. Generally, powder grain size can influence its temperature and melting time, with smaller grains melting faster. Since the same feed material was used and only the maximum incorporation time is considered, this factor can also be ignored. The temperature of the melt pool could also affect incorporation times, where the lower incorporation times would be expected with melt pools with higher temperatures. This trend is seen for the copper, steel and titanium alloy substrates, while it does not apply to the aluminium substrate (with the lowest melting temperature among the materials considered). The most significant factor to affect incorporation time can be considered to be the surface tension forces, which are based on the composition of the melt pool and its temperature [23]. Additionally, wettability of the different molten materials on solid copper and viscosity of the molten materials can also have an influence in incorporation. A trend regarding density of the molten materials and the maximum incorporation time is seen, without it necessarily being a cause. The higher the density of the melt, the longer

Table 4 Melt pool length, track width, track height, melting depth, dilution, percentage of laser power used purely for melting and incorporation time observed for copper powder deposited onto copper,

\begin{tabular}{llllllrr}
\hline Substrate material & $\begin{array}{l}\text { Melt pool } \\
\text { length }(\mathrm{mm})\end{array}$ & $\begin{array}{c}\text { Track width } \\
(\mathrm{mm})\end{array}$ & $\begin{array}{c}\text { Track height } \\
(\mathrm{mm})\end{array}$ & $\begin{array}{c}\text { Melting depth } \\
\text { in substrate }(\mathrm{mm})\end{array}$ & $\begin{array}{c}\text { Dilution } \\
(\%)\end{array}$ & $\begin{array}{c}\text { Laser power used } \\
\text { for melting }(\%)\end{array}$ & $\begin{array}{c}\text { Incorporation } \\
\text { time }(\mathrm{ms})\end{array}$ \\
Copper & - & 1.04 & 0.26 & 0 & 0 & 0.73 & 0.3 \\
Aluminium & 1.74 & 1.4 & 0.24 & 0.306 & 53.2 & 2.94 & 0.1 \\
Steel & 2.60 & 2.34 & 0.14 & 0.382 & 77.5 & 5.15 & 0.2 \\
Titanium alloy & 6.49 & 2.96 & 0.26 & 0.706 & 76.2 & 9.78 & 0.1 \\
\hline
\end{tabular}

the measured maximum incorporation times (densities are $8960 \mathrm{~kg} / \mathrm{m}^{3}$ for copper and $7810 \mathrm{~kg} / \mathrm{m}^{3}$ for steel 1.2343 at room temperature; $7998 \mathrm{~kg} / \mathrm{m}^{3}$ for pure copper [4], $4030 \mathrm{~kg} /$ $\mathrm{m}^{3}$ for Ti6Al4V [19] and $2372 \mathrm{~kg} / \mathrm{m}^{3}$ for pure aluminium [3] at their melting points).

The presence of the oxide skin on the surface of the melt pool varies between the four substrates. It is seen on the aluminium, steel and titanium alloy substrates, but it varies in quantity and stability. The oxide skin on the aluminium melt pool covers a large fraction of the melt pool and has the greatest impact on incorporation of the powder grains. It is segmented and scanty on the steel and titanium alloy melt pools, which is a possible reason why the copper powder grains are not seen to float on the oxide skin in these cases. It is also likely to be thinner than the oxide skin on the aluminium melt pool. The copper and aluminium substrates were sandblasted directly prior to cladding, removing surface oxides. Aluminium has a stronger tendency to oxidise than copper. An oxide skin is not visible in the high-speed videos for the copper substrate. Copper oxides are unstable at high temperatures, although they have a higher melting point than pure copper $\left(1336{ }^{\circ} \mathrm{C}\right.$ for $\mathrm{CuO}, 1230^{\circ} \mathrm{C}$ for $\mathrm{Cu}_{2} \mathrm{O}$ and $1083{ }^{\circ} \mathrm{C}$ for pure $\mathrm{Cu}$ ). Depending on the temperature of the melt pool, the oxides may be molten, or create a thin layer that does not have a significant effect with respect to powder incorporation. Their

aluminium, steel and titanium alloy substrates for the same parameters: laser power $1 \mathrm{~kW}$, cladding speed $0.5 \mathrm{~m} / \mathrm{min}$ and powder feed rate $1.3 \mathrm{~g} /$ $\min$ 
biggest significance is likely to be between different layers deposited by reducing wettability [17].

Absorptivity of the green laser beam in the different substrate materials is a significant reason for the different melt pool dimensions seen in Fig. 8 and Table 4. From the data of Spisz et al. [21] as in Fig. 1, the percentages of spectral absorptance for copper, aluminium, stainless steel and titanium for the green laser are 55\%, 13\%, 40\% and $78 \%$ respectively for smooth surfaces. Note that these values can strongly shift (either increase or decrease) based on alloying elements added to the metals. The copper and aluminium substrates used were sandblasted, texturing their surfaces, likely increasing absorption. The melt pool dimensions are as expected from the absorption values for aluminium, steel and the titanium alloy. Although 55\% of the laser light irradiated on the copper substrate is expected to be absorbed, the melt pool generated is the smallest among the four substrate materials for the same parameter set.

A very small fraction of the laser energy irradiated on the surface of the metals is found to be used purely for melting both the substrate material and the deposited clad. In the case of copper, $0.73 \%$ of the irradiated energy is calculated to be used for melting. In the case of the titanium alloy, where the largest melt pool is formed, 9.78\% of the laser energy irradiated is accounted for in melting of material. The remaining energy is reflected, scattered or conducted away from the melt pool, influenced by the thermal properties of the materials.

In similar calculations made for the copper wall seen in Fig. 3, 2.66\% of the power irradiated was calculated to be used in melting of material. Compared with copper deposition on a copper substrate, the fraction of the energy used for melting in the wall is four times higher. This is due to reduced workpiece heating. Only the physical properties of copper were considered, since only the first layer of the clad was built on the steel substrate. Calculations for LMD by Brückner [7] have previously shown that only about $2.7 \%$ of the power supplied to the laser unit, or $9.5 \%$ of the energy radiated on the surface of the metal, is used in formation of a layer. Hofmeister et al. [11] observe that heat conduction is the greatest for the first deposited layer on the substrate and there is heat accumulation on thinwalled structures.

As the thermal conductivity increases, the amount of heat conducted away from the melt pool increases, implying that a material with high thermal conductivity would form a smaller melt pool than a material with low thermal conductivity. The order of decreasing values of thermal conductivity is as follows: copper $(385 \mathrm{~W} / \mathrm{mK})$, aluminium $(205 \mathrm{~W} / \mathrm{mK})$, steel $1.2343(42.2 \mathrm{~W} / \mathrm{mK})$ and titanium alloy Ti6Al4V $(7.2 \mathrm{~W} / \mathrm{mK})$. The size of the melt pools follows this trend as can be seen in Fig. 8 and Table 4.
The order of increasing melt pool length and track width is as follows: copper, aluminium, steel and titanium alloy substrates. The same trend is seen with regard to thermal diffusivity. It is obvious that melt pool width and length are correspondent to the thermal conductivity of the materials. However, some additional factors also play a role in defining melt pool size and shape such as convection, wettability, absorptivity and vaporisation.

In the case of the steel specimen in Fig. 8, longitudinal cracks can be seen (Fig. 8(a)(iii) and (b)(iii)). The cracks form because of thermal stresses in the solidifying clad on the tool steel substrate. It has been seen in studies regarding welding of copper and tool steel that hot cracking is an issue. When there is a mixing of copper and steel melt, steel solidifies before copper; copper melt can then penetrate into the grain boundaries of solidified steel [14]. When the feed rate was increased in the experiments presented in this paper (Fig. 6), more energy was used for melting copper rather than melting the base material. This changed the thermal cycle and reduced the mixing with the base material (tool steel), resulting in no cracks. The longitudinal cracks formed during solidification can therefore be related to the material composition and thermal stresses in the deposited clad and the base material.

From the high-speed imaging frame seen in Fig. 8(a)(i), it can be seen that the melt pool formed on the copper substrate is very small with a length less than $0.5 \mathrm{~mm}$ and patchy (not continuous), producing $0 \%$ dilution. The powder grains in LMD often interact with the laser beam before reaching the surface of the substrate or the melt pool or the substrate. Effects like multiple reflections and small volume of powder grains decrease the power required for a temperature rise compared with a dense material. This can cause the surface of the powder grains to start melting, leading to the sintering effect that can be seen in the case of the clad with the copper substrate (at cladding speed $0.5 \mathrm{~m} / \mathrm{min}$ ). The cross-section image (Fig. 8(c)(i)) shows porosity and there is no dilution. Preheating of the substrate to raise its temperature would increase the absorption of the laser radiation [5], and increase the chance of forming a melt pool, which in turn promotes formation of a larger melt pool (since the increase in absorptivity is in the order of $150-200 \%$ after the solid-liquid transition, when it continues to increase linearly).

\section{Conclusions}

Laser metal deposition of copper on copper, aluminium, steel and titanium alloy substrates was carried out with a 515-nm wavelength laser system and observed through high-speed imaging.

- The copper substrate required the highest power and the slowest cladding speed to form a continuous melt pool and 
clad. Aluminium, steel and titanium alloy substrates follow the order of decreasing laser power requirement for the same cladding speed. Size and geometry of the melt pool in the process depend on multiple physical and thermal factors of the substrates as well as process parameters.

- Incorporation of the copper powder grains in the melt is very fast and occurs within $0.1 \mathrm{~ms}$ for aluminium and titanium alloy substrates, but can be 0.2 and $0.3 \mathrm{~ms}$ for the steel and copper substrates respectively. It is affected by a complex interdependence of multiple material properties including melt pool temperatures, melting temperatures for the various materials, viscosity and surface tension-driven forces.

- The oxide skin present on melt pools can have a strong influence on powder incorporation in the case of the aluminium substrate. The scanty oxide skins on the melt pools of steel and titanium substrates have little effect on powder incorporation. No oxide skin was seen on the copper melt pool.

- The high angle and small size of the melt pool during deposition on the copper substrate along with the longer incorporation time make the probability of powder catchment lower than that for the other substrate materials. Preheating of the substrate might improve wettability, and thus the melt pool geometry and the catchment efficiency.

- The lower limit of percentage of laser power used purely for melting of material was lowest for a single track at $0.73 \%$ (2.66\% in a multilayer build) for copper deposition on copper substrate, $2.94 \%$ for the aluminium substrate, $5.15 \%$ for the tool steel substrate and highest at $9.78 \%$ for the titanium alloy substrate. These values are strongly influenced by the degree of absorptance of laser radiation and the thermal conductivity of the materials. The remaining power is reflected, scattered or used for workpiece heating.

Acknowledgements Open access funding provided by Lulea University of Technology.

Funding information The work concerning this paper was funded by EU Interreg Nord, project C3TS No. 304-10694-2017 and EIT RawMaterials, Project SAMOA No. 18079.

Open Access This article is licensed under a Creative Commons Attribution 4.0 International License, which permits use, sharing, adaptation, distribution and reproduction in any medium or format, as long as you give appropriate credit to the original author(s) and the source, provide a link to the Creative Commons licence, and indicate if changes were made. The images or other third party material in this article are included in the article's Creative Commons licence, unless indicated otherwise in a credit line to the material. If material is not included in the article's Creative Commons licence and your intended use is not permitted by statutory regulation or exceeds the permitted use, you will need to obtain permission directly from the copyright holder. To view a copy of this licence, visit http://creativecommons.org/licenses/by/4.0/.

\section{References}

1. Arata Y, Abe N, Oda T (1985) Fundamental phenomena in high power CO2 laser welding (report I): atmospheric laser welding (welding physics, process \& instrument). Trans JWRI 14:5-11

2. Asano K, Tsukamoto M, Funada Y, Sakon Y, Abe N, Sato Y, Higashino R, Sengoku M, Yoshida M (2018) Copper film formation on metal surfaces with $100 \mathrm{~W}$ blue direct diode laser system. J Laser Appl 30:032602. https://doi.org/10.2351/1.5040635

3. Assael MJ, Kakosimos K, Banish RM, Brillo J, Egry I, Brooks R, Quested PN, Mills KC, Nagashima A, Sato Y, Wakeham WA (2006) Reference data for the density and viscosity of liquid aluminum and liquid iron. J Phys Chem Ref Data 35:285-300. https:// doi.org/10.1063/1.2149380

4. Assael MJ, Kalyva AE, Antoniadis KD, Michael Banish R, Egry I, Wu J, Kaschnitz E, Wakeham WA (2010) Reference data for the density and viscosity of liquid copper and liquid tin. J Phys Chem Ref Data 39:033105. https://doi.org/10.1063/1.3467496

5. Bergström D (2008) The absorption of laser light by rough metal surfaces. Dr. Thesis. Luleå University of Technology

6. Bourell D, Kruth JP, Leu M, Levy G, Rosen D, Beese AM, Clare A (2017) Materials for additive manufacturing. CIRP Ann 66:659 681. https://doi.org/10.1016/j.cirp.2017.05.009

7. Brückner F (2011) Modellrechnungen zum Einfluss der Prozessführung beim induktiv unterstützten Laser-PulverAuftragschweißen auf die Entstehung von thermischen Spannungen, Rissen und Verzug. Fraunhofer IWS

8. Brueckner F, Riede M, Müller M, Marquardt F, Willner R, Seidel A, Lopéz E, Leyens C, Beyer E (2018) Enhanced manufacturing possibilities using multi-materials in laser metal deposition. J Laser Appl 30:032308. https://doi.org/10.2351/1.5040639

9. Gibson I, Rosen D, Stucker B (2014) Additive manufacturing technologies. Springer, New York. https://doi.org/10.1007/978-1-49392113-3

10. Hess A, Schuster R, Heider A, Weber R, Graf T (2011) Continuous wave laser welding of copper with combined beams at wavelengths of $1030 \mathrm{~nm}$ and of $515 \mathrm{~nm}$. Phys Procedia 12:88-94. https://doi.org/ 10.1016/j.phpro.2011.03.012

11. Hofmeister W, Griffith M, Ensz M, Smugeresky J (2001) Solidification in direct metal deposition by LENS processing. JOM 53:30-34

12. Imran MK, Masood SH, Brandt M, Bhattacharya S, Mazumder J (2011) Direct metal deposition (DMD) of H13 tool steel on copper alloy substrate: evaluation of mechanical properties. Mater Sci Eng A 528:3342-3349. https://doi.org/10.1016/j.msea.2010.12.099

13. Lykov P, Baytimerov R, Vaulin S, Safonov E, Zherebtsov D (2016) Selective laser melting of copper by $200 \mathrm{~W} \mathrm{CO} 2$ laser, in: SAE technical paper series, pp 284-288. https://doi.org/10.4271/201601-0333

14. Mai TA, Spowage AC (2004) Characterisation of dissimilar joints in laser welding of steel-kovar, copper-steel and copper-aluminium. Mater Sci Eng A. https://doi.org/10.1016/j.msea.2004.02.025

15. Mazumder J (1991) Overview of melt dynamics in laser processing. Opt Eng 30:1208-1219

16. Mazumder J, Stiles E (2000) Fabrication of designed materials using direct metal deposition, in: International Congress on Applications of Lasers \& Electro-Optics. Laser Institute of America, pp E13-E21. https://doi.org/10.2351/1.5059537

17. Pogson SR, Fox P, Sutcliffe CJ, O'Neill W (2003) The production of copper parts using DMLR. Rapid Prototyp J 9:334-343. https:// doi.org/10.1108/13552540310502239

18. Popovich A, Sufiiarov V, Polozov I, Borisov E, Masaylo D, Orlov A (2016) Microstructure and mechanical properties of additive manufactured copper alloy. Mater Lett 179:38-41. https://doi.org/ 10.1016/j.matlet.2016.05.064 
19. Schmon A, Aziz K, Pottlacher G (2017) Density of liquid Ti-6Al4V. In: EPJ Web of Conferences, 16th International Conference on Liquid and Amorphous Metals (LAM-16), p 04003 https://doi.org/ 10.1051/epjconf/201715104003

20. Siva Prasad H, Brueckner F, Kaplan AFH (2019) Powder catchment in laser metal deposition. J Laser Appl 31:022308. https://doi. org/10.2351/1.5096130

21. Spisz EW, Weigund AJ, Bowmun RL, Juck JR (1969) Solar absorptances and spectral reflectances of 12 metals for temperatures ranging from 300 to $500 \mathrm{~K}$. NASA, Tn D-5353
22. Tolochko NK, Khlopkov YV, Titov VI, Ignatiev MB, Mozzharov SE, Laoui T (2002) Absorptance of powder materials suitable for laser sintering. Rapid Prototyp J 6:155-161. https://doi.org/10. $1108 / 13552540010337029$

23. Volpp J (2019) Behavior of powder particles on melt pool surfaces. Int J Adv Manuf Technol 102:2201-2210. https://doi.org/10.1007/ s00170-018-03261-1

Publisher's note Springer Nature remains neutral with regard to jurisdictional claims in published maps and institutional affiliations. 